\title{
The proteasome-ubiquitin pathway in the Schistosoma mansoni egg has development- and morphology-specific characteristics
}

\author{
William Mathieson*, William Castro-Borges ${ }^{1}$, R. Alan Wilson \\ Department of Biology, University of York, PO Box 373, York YO10 5YW, UK
}

\section{A R T I C L E I N F O}

\section{Article history:}

Received 30 July 2010

Received in revised form 12 October 2010

Accepted 13 October 2010

Available online 21 October 2010

\section{Keywords:}

Hatch fluid

Miracidium

Vitelline cells

Vitellaria

SEA

\begin{abstract}
A B S T R A C T
Schistosoma mansoni eggs, consisting of an ovum surrounded by nutritive vitelline cells packaged in a tanned protein shell, are produced by paired worms residing in the mesenteric veins of the human host. The vitelline cells are degraded as the larval miracidium matures, the fully developed egg either crossing the gut wall to escape the host or becoming lodged in the host's tissues where it dies and disintegrates, inducing a potentially pathological immune response. Thus, the egg is central to both the transmission of the parasite and the aetiology of the disease. Here we present the first study investigating protein turnover in the egg. We establish that the ubiquitin-proteasome pathway (UPP) changes with egg development and furthermore, that the morphological components of the fully developed egg (the miracidium and the subshell envelope) also exhibit different proteasome subunit expression profiles. We conclude that the UPP is responsible not only for degrading the vitelline cells but is also more highly developed in the envelope than in the miracidium. The envelope is involved in the defence of the miracidium and produces the proteins that the egg secretes, presumably to facilitate its escape from the host, so the UPP probably has a multi-faceted role in the egg's biology.
\end{abstract}

(C) 2010 Elsevier B.V. All rights reserved.

\section{Introduction}

The ubiquitin-proteasome pathway (UPP) is an intracellular system in which large, multi-subunit, non-specific proteolytic machines called proteasomes degrade proteins that have been tagged with chains of ubiquitin. The UPP is involved in numerous processes, from the recycling of damaged proteins to the regulation of the cell cycle, apoptosis and transcription [1-3]. Proteasomes are comprised of $\alpha$ and $\beta$ subunits that assemble as seven-member rings. Four rings stack together to form a barrel-like particle in the conformation $\alpha_{1-7}, \beta_{1-7}, \beta_{1-7}, \alpha_{1-7}$, called the $20 \mathrm{~S}$ proteasome [4-6]. It has six proteolytic subunits with active sites pointing towards the centre of the ring, a structure ensuring that uncontrolled degradation of proteins is avoided by confining proteolysis to the internal chamber of the proteasome [7]. The proteolytic subunits are located at the $\beta_{1}, \beta_{2}$ and $\beta_{5}$ positions and have different substrate specificities ( $\beta_{1}$; caspase-like, $\beta_{2}$; trypsin-like and

Abbreviations: ESP, egg secreted proteins; PIP, proteasome interacting proteins; SEA, soluble egg antigen; UPP, ubiquitin-proteasome pathway.

* Corresponding author. Present address: Department of Surgery and Cancer, Imperial College London, DuCane Road, London W12 0NN, UK.

Tel.: +44 (0) 2083832445 .

E-mail address: bill.mathieson@imperial.ac.uk(W. Mathieson).

1 Present address: Department of Biological Sciences, Federal University of Ouro Preto, Ouro Preto, Brazil. $\beta_{5}$; chymotrypsin-like). Acting in consort, they degrade most proteins to peptides of 3-22 amino acids in length, depending on their amino acid sequence [8]. The post-proteasomal peptides are then further degraded into their constituent amino acids in the cytosol by conserved families of endopeptidases, aminopeptidases and carboxypeptidases [9]. Target proteins enter the 20S proteasome through the aperture in the centre of either outer $\alpha$-subunit ring, the process being controlled by a multi-subunit component called the 19S regulatory complex (also known as PA700), which caps the $20 \mathrm{~S}$ proteasome. The $19 \mathrm{~S}$ regulatory complex recognises the ubiquitin tag, cleaves off the ubiquitins one-by-one (for reuse), unwinds the substrate protein and feeds it into the $20 \mathrm{~S}$ proteasome. The active proteasome, consisting of the 20S proteasome core plus its $19 \mathrm{~S}$ regulatory complex is called the $26 \mathrm{~S}$ proteasome (30S when doubly capped). Both the 20S proteasome core and the $19 S$ regulatory subunits undergo post-translational modifications, including phosphorylation, N-acetylation and O-GlcNAc glycosylation [10-14]. Regulation also occurs via a family of proteins called "proteasome interacting proteins"(PIPs) that associate with the 19S regulatory complex [15].

Ubiquitin is a multi-functional $8.5 \mathrm{kDa}$ protein of 76 amino acids, best known for its role in the UPP. The tag recognised by the 19S proteasome regulatory complex consists of a chain of at least four ubiquitins, where the C-terminus of each ubiquitin is linked to lysine 48 of the preceding ubiquitin [16]. However, other forms of protein ubiquitinylation are commonplace: a single ubiquitin can be attached to the substrate (mono-ubiquitinylation), or several 
ubiquitins attached to different residues (multi-ubiquitinylation). A lysine-63-linked poly-ubiquitin chain attached to a substrate protein is associated with non-proteolytic functions such as endocytosis, signal transduction, transcriptional regulation, ribosome function and DNA-repair pathways [17]. Ubiquitin's central structure, the "ubiquitin superfold" is also incorporated into much larger proteins, collectively called "ubiquitons". These are less-well studied, but they include kinases and kinase-interacting proteins, so are likely to be involved in signal transduction [18-20]. Ubiquitons have also been identified as transport proteins that bind to polyubiquitinylated proteins and transport them to the $26 \mathrm{~S}$ proteasome for destruction [21-23].

Schistosomiasis is a tropical parasitic disease caused by trematode worms of the genus Schistosoma. Adult S. mansoni reside in the mesenteric veins producing eggs, some of which pass through the tissues of the gut wall, enter the gut lumen, exit the host in faeces and rupture when encountering fresh water to release the miracidium larva. However, some eggs fail to adhere to the mesenteric venous epithelium and are washed away in the bloodstream to become lodged in the portal venules of the liver. Here they mature, secrete proteins, then die and disintegrate, inducing a granulomatous response which causes severe pathology in some individuals [24]. Thus, the egg and its development are crucial in the aetiology of the disease.

The newly released schistosome egg consists of an ovum surrounded by vitelline cells encased in a cross-linked protein shell $[25,26]$. It takes a week to mature, during which time the vitelline cells degrade, providing nutrients for the developing miracidium. A syncytial envelope, known as "von Lichtenberg's envelope" [25] forms between the developing miracidium and the shell, and produces a simple mixture of proteins termed egg secreted proteins (ESP). At least one protease is present, presumably required to facilitate the egg's escape through the host tissues [26,27]. The space between the miracidium and the envelope contains a viscous liquid called hatch fluid and large vesicles that could be the remains of spent vitelline cells. Hatch fluid is enriched in defence proteins which probably offer the miracidium and the envelope protection from toxins derived from host leukocytes [27]. Thus, the fully developed S. mansoni egg is multifaceted, with its contents (the miracidium, ESP and hatch fluid) having markedly differing roles. Although Mathieson and Wilson [27] found the miracidial, ESP and hatch fluid proteomes to be markedly different, reflecting their respective functional roles, it is noteworthy that the differences were less clear-cut for those proteins involved in protein turnover, principally the proteins of the UPP.

The UPP has previously been studied in S. mansoni cercariae, lung-worms and adults $[28,29]$. In the mouse model, proteasome inhibitors prevent larval development and reduce adult worm burden [28]. Although each of the fourteen S. mansoni proteasomal subunits are encoded by a single copy gene, they separate into 58 spots on a 2D gel, so they must be post-translationally modified [30]. In the spot-pattern for each subunit, a single large intensely staining spot lies in close proximity to several smaller spots which differ slightly in charge but not mass, suggesting that the post-translational modifications consist of different degrees of phosphorylation. When 2D Western blots of adult and cercarial preparations were probed with an antibody that recognises $20 \mathrm{~S}$ proteasome $\alpha$-subunits, Castro-Borges et al. [30] were able to show that the spot patterns were different in each preparation, thereby demonstrating that the pattern of post-translational modification differed in the two life-cycle stages.

The work in this paper follows on from the Guerra-Sa et al. [28] and Castro-Borges et al. [30] papers. The extent to which 20S $\alpha$-subunit expression changes as the egg develops was assessed by comparing 2D Western blots of a vitellaria-enriched preparation (Vit) from adult females (representing the egg's vitelline cells), an undeveloped egg preparation (SEAu) and a fully developed egg preparation (SEAd). In vitro fluorogenic substrate assays were used to determine whether the changes in $\alpha$-subunit expression revealed by blotting could be linked to the proteolytic activity of the proteasome. Western blotting was also used to compare the proteasome $\alpha$-subunit expression pattern in a miracidial preparation (Ms) and a hatch fluid preparation containing envelope proteins (Hf) to gain insights into how the UPP might be employed by the egg to aid its passage through the gut wall and successfully emerge into the gut lumen. The extent of ubiquitinylation in SEAu, SEAd, Ms and Hf was then established by blotting and linked back where possible to the information obtained with regard to proteasomal expression and activity.

\section{Materials and methods}

\subsection{Parasite material}

Male C57BL/6xCBA mice were each infected with 180 cercariae of a Puerto Rican isolate of S. mansoni via the shaved abdomen [31]. Seven weeks later the mice were euthanized by $\mathrm{CO}_{2}$ inhalation and eggs at all stages of development were recovered from their livers by trypsin digestion, then cleaned by washing and sieving [26]. Ethical Approval for this work was granted by the University of York Ethics Committee and all animal procedures were carried out within the Codes of Practice of the United Kingdom's Animals (Scientific Procedures) Act (1986). Egg preparations were made as previously described [27], but briefly, undeveloped eggs were separated from developed eggs using a Percol gradient. SEAu and SEAd were made by grinding either immature eggs or mature eggs in M3 buffer (7 M urea, $2 \mathrm{M}$ thiourea, $4 \%$ CHAPS and protease inhibitor cocktail (all Sigma, Poole, UK)), centrifuging them and retaining the supernatant. Ms and Hf were made by hatching mature eggs in a glass test-tube. Transverse illumination attracted the miracidia to the top of the tube; these were collected by filtration then processed as in SEAu and SEAd to make Ms. The bottom $3 \mathrm{ml}$ of test tube sample (consisting of extracellular hatch fluid proteins and intracellular envelope proteins washed from the eggs as the miracidia emerged) was gravity-filtered, concentrated and then solubilised in M3 buffer to produce Hf. Adult worms were recovered from infected mice by portal perfusion with RPMI-1640 (Gibco, Renfrew, UK) to which 10\% FCS, 2.5\% HEPES and 5 units heparin/ml (all Sigma) had been added. Paired females were separated from males using two fine brushes and then washed three times in RPMI-1640 to remove the FCS. The females were then severed laterally immediately below the ventral sucker and the posterior sections (containing the vitellaria) transferred into $200 \mu \mathrm{l}$ M3 buffer containing $10 \%$ glycerol (Sigma). Once approximately 50 worm posteriors had been collected in this way the 'Vit' preparation was made by grinding and centrifuging the sample in the same way as in SEA and Ms.

\subsection{Western blotting}

Soluble proteins were fractionated by standard twodimensional electrophoresis techniques [32]. Samples containing $35 \mu \mathrm{g}$ of SEAu, SEAd, Ms, Hf and Vit were adjusted to $125 \mu \mathrm{l}$ with re-hydration buffer (M3 buffer containing $\mathrm{pH}$ 3.5-10 resolytes (BDH, VWR International, Dorset) plus DTT and bromophenol blue (both Sigma)). The preparations were then separated according to their charge by isoelectric focusing (IEF) in $7 \mathrm{~cm}, \mathrm{pH} 3-10$ IEF strips (Applied Biosystems, Warrington, UK) using the following protocol: $12 \mathrm{~h}$ rehydration followed by $500 \mathrm{~V}(30 \mathrm{~min}), 1000 \mathrm{~V}$ (30 min) and then at $50 \mu \mathrm{A}$ for $4 \mathrm{~h}$. Focussed proteins were reduced (1\% DL-dithiothreitol (Sigma)) and alkylated (4\% iodoacetamide (Sigma)) and then the IEF strips were transferred to the top of 
$7 \mathrm{~cm}$ NuPAGE 4-12\% Bis-Tris gels (Invitrogen, Renfrew, UK). The proteins were then separated by molecular mass by applying $200 \mathrm{~V}$ for $40 \mathrm{~min}$. Immediately after electrophoresis, each gel was placed on $8.3 \mathrm{~cm} \times 7.3 \mathrm{~cm}$ Invitrolon $0.2 \mu \mathrm{m}$ polyvinylidenefluoride (PVDF) membrane (Invitrogen) and installed in an XCell II Blot Module (Invitrogen). The blot module was filled with NuPAGE transfer buffer (Invitrogen) and the proteins transferred from the gel to the membrane by applying a constant current of $30 \mathrm{~V}$ for $75 \mathrm{~min}$. Successful protein-transfer was confirmed by staining the membrane with Sypro Ruby protein blot stain (Bio-Rad, Hemel Hempstead, UK) and imaging it using a Versa Doc (Bio-Rad). The blots were probed with mouse anti-human $20 \mathrm{~S}$ proteasome IgG (Biomol, Exeter, UK), which recognises S. mansoni proteasome $\alpha$-subunits [30], then detected with goat anti-mouse IgG peroxidase conjugate (Sigma). The image was visualised using the ECL Plus Western Blotting Detection System with Hyperfilm ECL paper (both GE Healthcare, Little Chalfont, UK) processed in a Compact X4 automatic film processor (Xograph, Tetley, UK). After imaging, each blot was washed and Restore Western Blot Stripping Buffer (Pierce, Cramlington, UK) was used to strip the blots of their antibodies. The blots were then probed with polyclonal rabbit anti-ubiquitin IgG (Sigma), which recognises mono-, multi- and poly-ubiquitinylated proteins. The detection antibody was goat anti-rabbit IgG alkaline phosphatase conjugate (Sigma) and the image was visualised using the chromogenic substrates 5-Bromo-4-Chloro-3-Indolyl phosphate/Nitro Blue Tetrazolium (Sigma).

\subsection{Measuring proteasomal activity in the undeveloped and fully developed egg}

Aliquots of undeveloped and developed eggs were ground for three minutes in $40 \mathrm{mM}$ Tris- $\mathrm{HCl}, \mathrm{pH} 7.5$ containing $5 \%$ glycerol and $1 \mathrm{mM}$ DTT, then the protein concentrations adjusted to $350 \mu \mathrm{g} / \mathrm{ml}$. Chymotrypsin-like activity was measured by incubating $75 \mu \mathrm{g}$ of each preparation at $37^{\circ} \mathrm{C}$ for $1 \mathrm{~h}$ in a 96 -well microtitre plate (Nunc, Roskilde, Denmark), with $25 \mu \mathrm{M}$ of the fluorogenic substrate $N$-Succinyl-Leu-Leu-Val-Tyr-7-amino-4methylcoumarin (Biomol) plus $5 \mathrm{mM} \mathrm{MgCl}_{2}$ (making a total volume of $240 \mu \mathrm{l}$ per well). In order to distinguish between $20 \mathrm{~S}$ proteasomal activity and non-proteasomal chymotrypsin-like activity, the assay was carried out in the presence and absence of $0.02 \%$ SDS (see Section 3.2 for rationale). After incubation, the reactions were terminated with $240 \mu \mathrm{l} /$ well of $1 \%$ SDS and the fluorescence measured on a Polarstar Optima plate reader (BMG Labtech, Aylesbury, $\mathrm{UK})$ at $320 \mathrm{~nm}$ excitation and $460 \mathrm{~nm}$ emission wavelengths. The fluorescence of the blank was deducted from the fluorescence of each assay and the results expressed as means ( \pm standard error of the mean) of duplicated assays. Non-proteasomal chymotryptic activity was measured by repeating the SDS ${ }^{-v e}$ assay with crude SEA (made from a mixture of immature and mature eggs) in the presence/absence of the proteasome-specific inhibitor epoxomicin (Biomol).

\section{Results}

\subsection{Proteasomal $\alpha$-subunit expression changes with egg development}

In order to assess how proteasomal subunit expression changed with egg development we compared 20S $\alpha$-subunit expression in the Vit blot (representing the vitelline cells) with the SEAu blot (made exclusively from undeveloped eggs) and the SEAd blot (made from fully developed eggs). Although $\alpha$-subunits were present in all the preparations, the spot-pattern on each blot was different.
The Vit preparation contained seven spots, which could be grouped into a row of five $30 \mathrm{kDa}$ spots of $\mathrm{pI} 5-7$ and two $25 \mathrm{kDa}$ spots of pI 4.5-5 (Fig. 1B). Two of the $30 \mathrm{kDa}$ spots were much fainter than all the other spots. This spot pattern was very distinctive, so all the other ECL images in the experiment could be matched to it exactly, thereby enabling between-preparation expression changes in individual isoforms to be seen (Fig. 1C). In the SEAu blot, all the spots had diminished in both size and intensity compared with the Vit blot, except that of the most acidic ( $25 \mathrm{kDa}$ ) isoform, which was now the largest spot by far. The more acidic of the two small, faint $30 \mathrm{kDa}$ spots in the Vit blot was not present in the SEAu blot. Spots continued to diminish in number between the SEAu and SEAd blots, such that only a single $25 \mathrm{kDa}$ isoform and a single $30 \mathrm{kDa}$ isoform were visible in the latter. Although the $30 \mathrm{kDa}$ spot had diminished in size, the $25 \mathrm{kDa}$ spot had not, remaining the same size as it was in the Vit blot.

\subsection{Proteasomal activity is greater in the undeveloped egg than in the developed egg}

As the SEAu blot contained more proteasomal $\alpha$-subunit isoforms than the SEAd blot, an assay was performed to compare the levels of chymotryptic activity in the two preparations, using a fluorogenic substrate in the presence and absence of $0.02 \%$ SDS. In the SDS ${ }^{-v e}$ assays the substrate is not degraded by 30 proteasomes because they are capped at both ends by 19S regulatory subunits and the substrate is not ubiquitinylated. Instead, the substrate is degraded by a combination of non-proteasomal chymotryptic proteases and 20S/26S proteasomes lacking 19 S subunits and/or interacting with PIPs. In the SDS ${ }^{+v e}$ assays however, nonproteasomal chymotryptic proteases are deactivated, PIPs and 195 regulatory subunits disassociate leaving all the proteasomes in the $20 \mathrm{~S}$ state and therefore capable of degrading the substrate [33,34]. The background level of non-proteasomal chymotryptic protease activity in the SDS ${ }^{-v e}$ assays was controlled for using the proteasomal inhibitor epoxomicin; these accounted for $54 \%$ of the total chymotryptic activity in the egg (Supplementary Fig. 1). Net of this, fluorescences in the SDS-ve assays were similar in SEAd (15.8 $\mathrm{kU} \pm 0.4)$ and SEAu (15.2 $\mathrm{kU} \pm 0.4)$, suggesting that they had equal concentrations of proteasomes in the $20 \mathrm{~S}$ and $26 \mathrm{~S}$ configurations (Fig. 1D). Adding SDS increased fluorescence by $150 \%$ in SEAd (to $39.6 \mathrm{kU} \pm 0.8$ ) and $271 \%$ in SEAu (to $56.4 \mathrm{kU} \pm 1.0$ ), so $26 \mathrm{~S}$ and $30 \mathrm{~S}$ proteasomal activity was 1.4 times higher in SEAu than in SEAd.

\subsection{Proteasomal $\alpha$-subunit expression differs in the subshell envelope and miracidium}

When the spot-patterns on the Hf blot (representing the subshell envelope) and the Ms blot (representing the miracidium) were compared with each other and with the SEAd blot it was possible to see which of the intra-egg preparations was enriched with proteasome $\alpha$ isoforms (Fig. 2). The Hf spot-pattern was completely different to that of any other blot, with three horizontal rows containing 16 spots of 25,30 and $50 \mathrm{kDa}, 10$ of which (including the $50 \mathrm{kDa}$ spots) were not present in any other preparation (Fig. 2B). The Ms blot contained six visible spots, all of which could be matched to hatch fluid spots, and three of which could be matched to the spots on the SEAd blot. Five out of the six Ms spots also matched spots from the Vit blot (Fig. 2C).

\subsection{Ubiquitinylation in the egg}

When the blots were stripped and re-probed with an anti-ubiquitin antibody (which recognises mono-, multi- and polyubiquitinylated proteins) many distinctive spot patterns were 
A
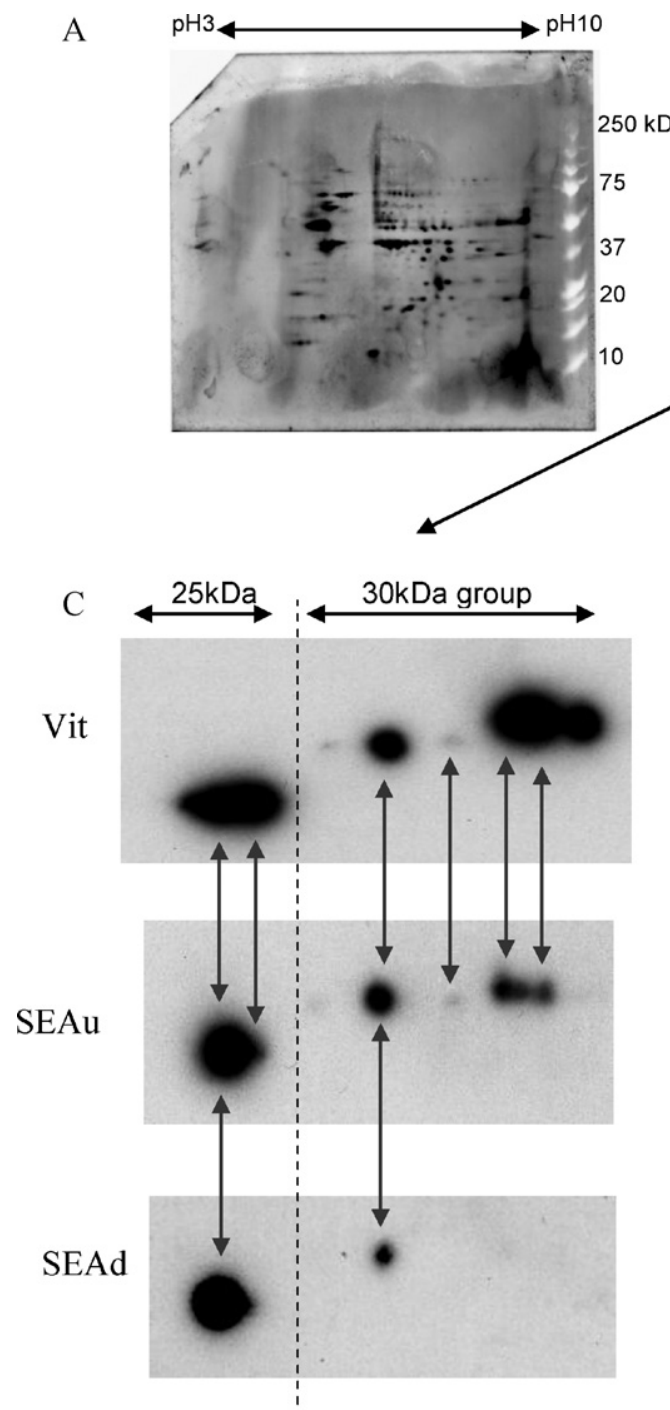

$\mathrm{B}$
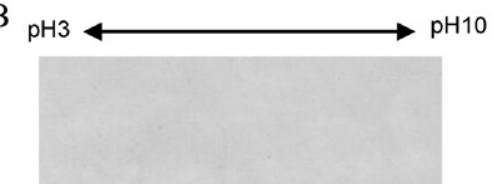

$25 \mathrm{kDa}$
D

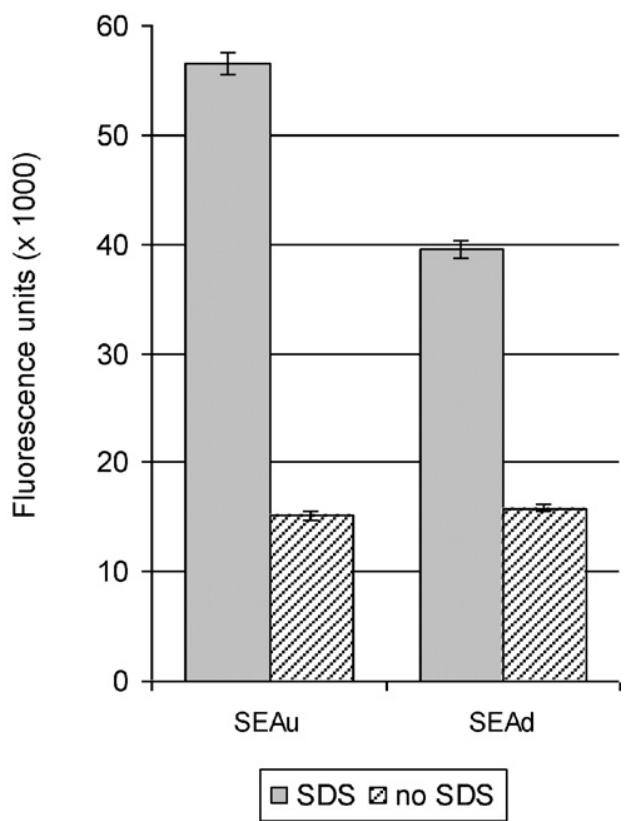

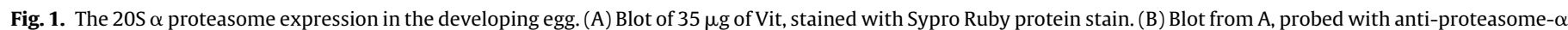

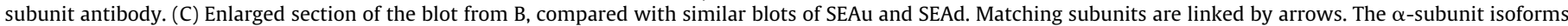

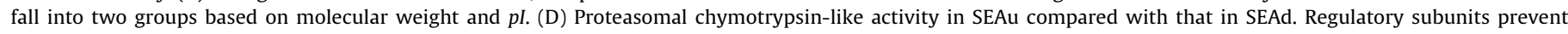

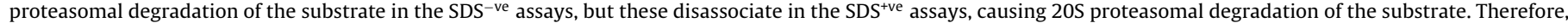
the $20 \mathrm{~S}$ proteasomal activity is represented by the difference between the fluorescence in the SDS ${ }^{+v e}$ and SDS ${ }^{-v e}$ assays.

apparent (Fig. 3). For example, the $15 \mathrm{kDa}$ slightly acidic proteins (annotated as "A" in Fig. 3) were in all the preparations, and the "B" series of spots was present in all of the blots except Ms. The very acidic protein " $\mathrm{C}$ " of $50-100 \mathrm{kDa}$ was the most heavily reacting protein on the blots in SEAu and SEAd and Hf, appeared as a faint spot in Vit and was not present in Ms. The location, size, shape and pattern of expression of the spot was similar to that of the previously described protein of unknown function Smp_170410 [27]. Some ubiquitinylated proteins were very abundant in Vit and SEAu, but had declined in abundance in SEAd ("D"). Unbound ubiquitin could be seen in the blots of SEAu and Ms ("E"), but not in SEAd or Hf.

\section{Discussion}

The S. mansoni egg needs to recycle proteins for radically different reasons depending on its stage of development. When undeveloped, the egg degrades its vitelline cells to nourish the embryo, but once fully developed and surrounded by host leukocytes, any damaged miracidial and envelope proteins require recycling. However, as far as we know, protein turnover has never been studied in trematode eggs before. In insects, developing eggs consist of the ovum and nurse cells which play a similar nutritive role as the vitelline cells of the schistosome egg [35]. The most detailed studies, involving Drosophila, show that cytoplasm is transferred from the nurse cells to the developing oocyte. Then, after the nurse cells have become apoptotic and their DNA has fragmented, their remnants are phagocytosed by somatic follicle cells [36,37]. Although these studies demonstrate that apoptosis is utilised in the final coup de gras of the nurse cells, they fall short of establishing what mechanisms are involved in the earlier stages of nurse cell degradation. Therefore, the UPP could be central to the degradation process of both nurse cells (in insects) and vitelline cells (in schistosomes). There is a fundamental difference between the situation in the schistosome egg and that in the insect egg however, in that the vitelline cells of the schistosome egg are not surrounded by follicular cells with a phagocytic capability. Neither the developing miracidium nor the envelope has been demonstrated to undertake phagocytosis, so it is unlikely that apoptosis has evolved to become important in vitelline cell degradation.

Our Western blots have shown that the 20S proteasome is more highly expressed in the undeveloped egg (SEAu) than in 
A

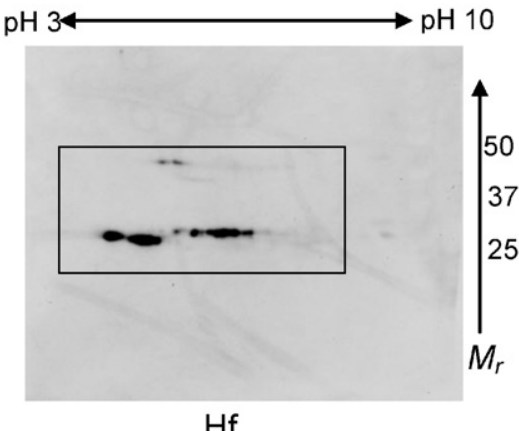

B

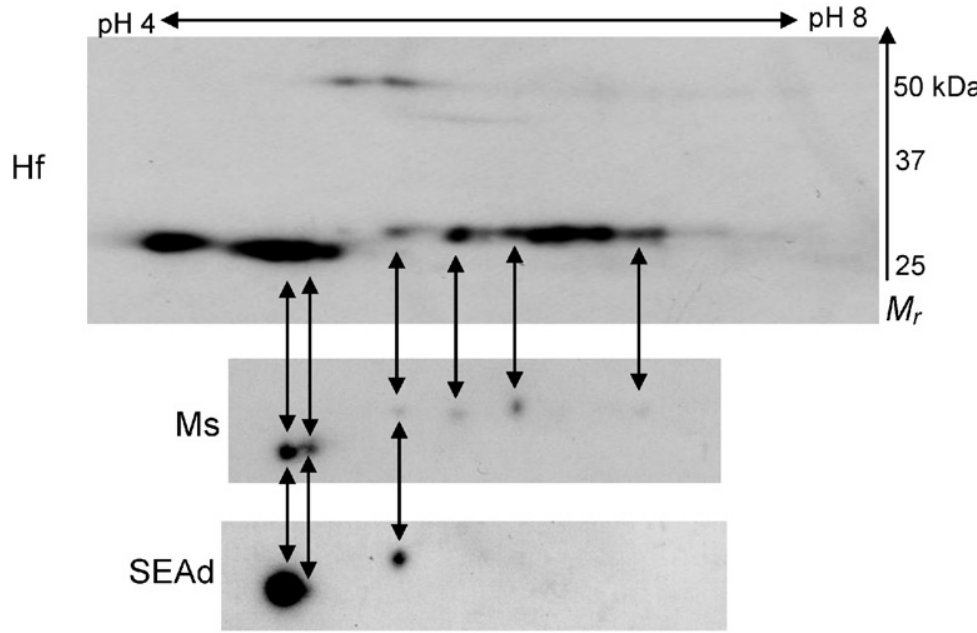

$\mathrm{C}$

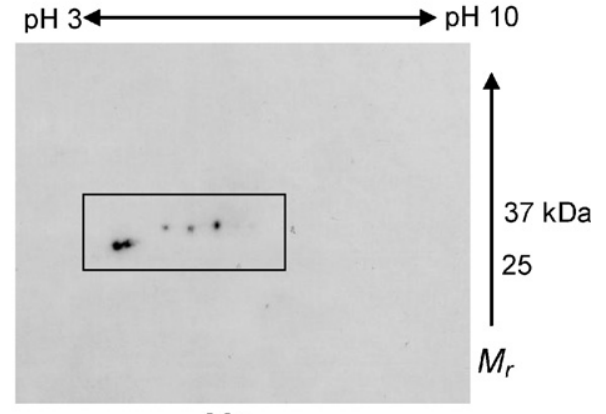

Ms
$7 \mathrm{kDa}$

5

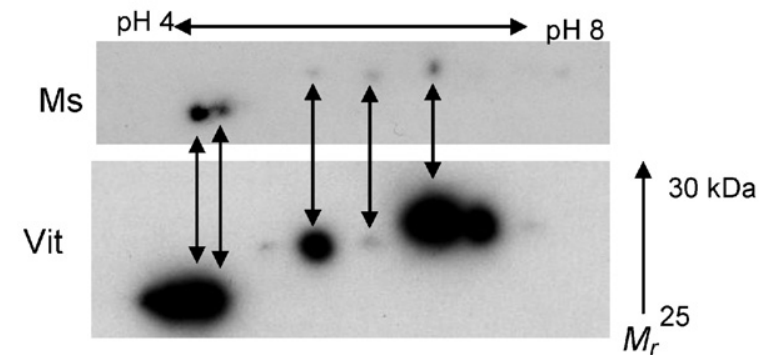

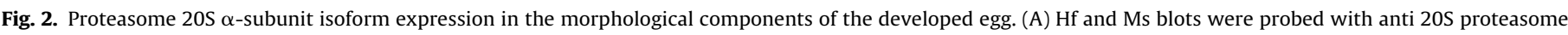

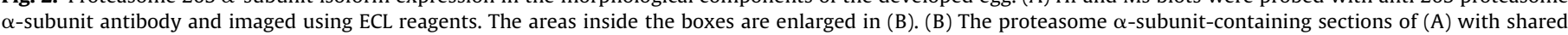
subunit isoforms shown by arrows. For comparison, the SEAd blot from Fig. 1C is also shown. (C) A similar comparison, but between the Ms and Vit blots.

the fully developed egg (SEAd), and our functional assays have demonstrated that proteasomal activity is also higher in the undeveloped egg. This decline in UPP utilisation with egg development could have two alternative explanations: (i) a reduction in damage inflicted by host leukocytes over time or (ii) the immature egg (the composition of which is dominated by vitelline cells) inherently utilizes the UPP more actively than the fully developed egg (containing the miracidium and envelope). Granulomata do not form around undeveloped eggs [38], the leucocytes only accumulating later in egg development, so it will be the more developed eggs that are in an environment with higher concentrations of toxic compounds. Also, the embryo is small in the immature egg, so the thick, protective layer of vitelline cells will buffer it from any host-derived toxins entering through the shell. Thus, the embryo of the undeveloped egg is likely to be at a lower risk of suffering damage from the products of host cells than the miracidium and envelope in the mature egg. Consequently, the more active UPP in the immature egg can most likely be attributed to some factor(s) relating to the function of the vitelline cells. As these cells have been proposed to provide an auto-degrading reservoir of nutrients for the developing ovum [39], we hypothesize that the UPP is relatively active in the immature egg because the UPP is the pathway by which this degradation occurs.

It is logical that the UPP would be used in this way because the process is highly regulated, both at the point where the substrate proteins are ubiquitinylated and at the proteasome itself. At the ubiquitinylation stage, E3 ubiquitin ligases determine which proteins are to be ubiquitinylated. Then, the speed at which ubiquitinylation takes place will depend on the availability of unbound ubiquitin. At the proteasome itself, a further level of regulation exists, not only with PIPs, but also with de-ubiquitinylation enzymes such as Ubp6, which can progressively remove ubiquitin moieties from substrate proteins to delay their proteasomal degradation [40]. Also, as proteasomal degradation is highly ATPdependent [41], intracellular ATP concentration will also determine the rate of activity. Thus, using the UPP rather than apoptosis or autophagy, the vitelline cells could degrade slowly, forming an amino acid-concentration gradient between themselves and the 

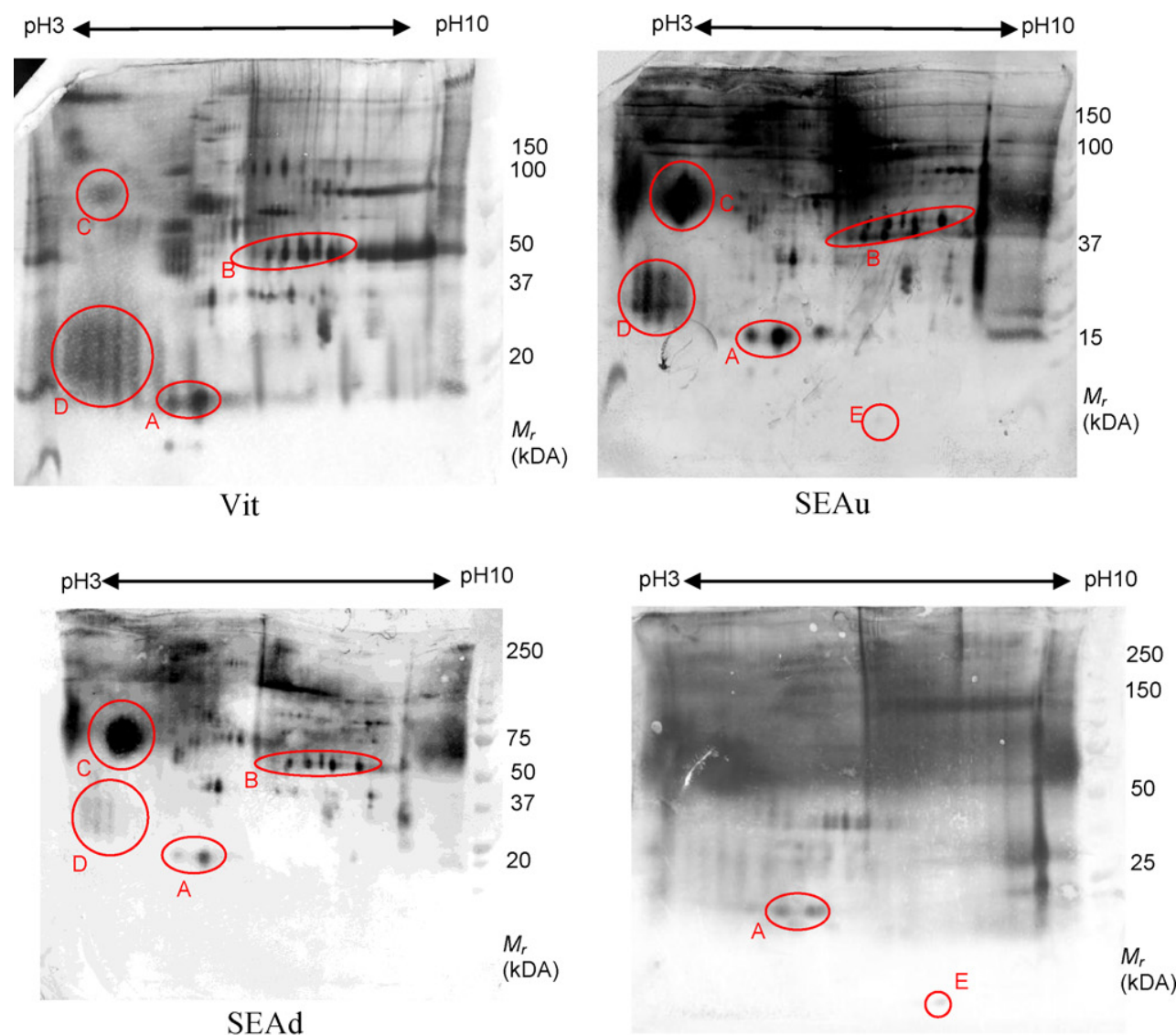

Ms

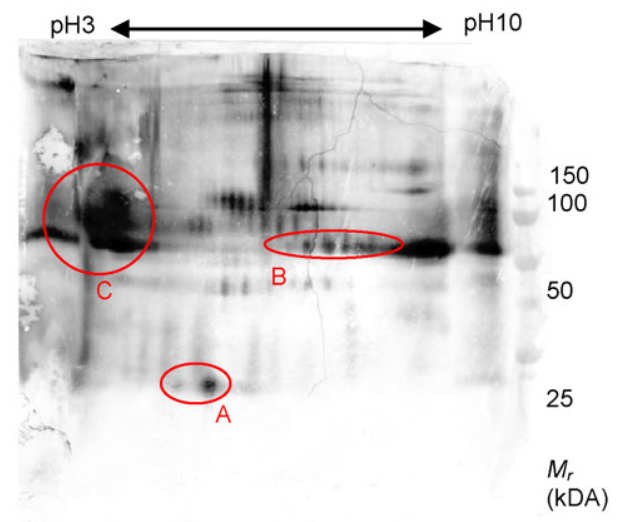

$\mathrm{Hf}$

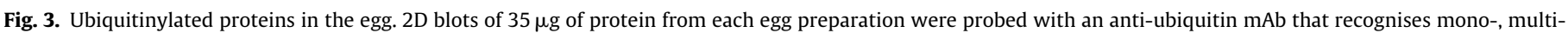
and poly-ubiquitinylated proteins. The blots were imaged using alkaline phosphatase reagents. The spots annotated A-F are discussed in the text.

developing miracidium, capable of delivering the amino acids that the miracidium requires for its growth.

There is little evidence that apoptosis is particularly active in schistosomes. The S. mansoni transcriptome was found to contain some but not all of the components of the apoptotic pathway [42]. Also, the apoptotic pathway is relatively uncontrollable once it has begun, with the process of caspase activation taking minutes to complete and then, once a cell is committed to undergo apoptosis the process is complete within several hours [43]. Thus, even if the apoptotic pathway was utilised in the egg, it is difficult to reconcile such a rapid mechanism of protein degradation with the slow and steady release of amino acids that the developing miracidium would require.
Autophagy is a more feasible process than apoptosis for vitelline cell degradation because almost all of the autophagic components have been found in the transcriptome and autophagy is known to occur in adult schistosomes $[42,44,45]$. Autophagy eliminates unwanted cells during developmental cell death in various taxa, including the ovarian nurse cells in Bombyx mori and Ceratitis capitata [46-48]. It is therefore possible that autophagy as well as the UPP is involved in the degradation of vitelline cells, perhaps with the UPP operating at the earlier stages and autophagy commencing at a later time point. The egg does not contain any phagocytic cells, so after their degradation, any vitelline cell remnants would remain inside the egg and possibly go on to form the vesicles of the fully mature egg. 
Although more proteasome $\alpha$ subunit isoforms were expressed in SEAu compared with SEAd, more expression was seen in the blots of the Vit preparation, enriched in vitellaria. The vitellaria occupy the posterior two-thirds of the female worm and consist of the vitelline ducts and follicles, the latter where the vitelline cells are produced [49]. Each female $S$. mansoni produces an estimated 200 eggs per day [50,51], each containing $30-40$ vitelline cells $[25,26]$, so the vitellaria are clearly very active in terms of protein production. During protein production, upwards of $30 \%$ of new proteins in various cell types are misfolded and are degraded by proteasomes $[52,53]$. It is therefore inevitable that the UPP will be highly active in the vitellaria and consequently, it is not surprising that the Vit preparation contained more proteasome $\alpha$-subunit isoforms than either SEAu or SEAd.

The mature egg can be sub-divided into the miracidium and the hatch fluid, represented by the Ms and Hf preparations respectively. Hatch fluid consists of extracellular proteins located either side of the envelope, the contents of the vesicles and those intracellular membrane proteins that are water-soluble. As the UPP is an intracellular system, all the proteasomal subunits and ubiquitinylated proteins on the Hf blot must have been derived from the envelope. In the proteasome $\alpha$-subunit blots, the spot-pattern in Ms is a sub-set of that in Hf. This could be partially due to the methods adopted to make each preparation. Hf only contains water-soluble proteins whilst Ms was made by homogenising miracidia in a buffer containing urea, thiourea and CHAPS. As proteasomal subunits are water-soluble they would have been enriched in Hf. However, the difference between the blots is probably too dramatic to be solely due to the different buffers. It is more likely that hatch fluid contains more $20 S \alpha$-subunit isoforms than the miracidial body because the UPP is more active in the envelope than in the miracidium. The envelope is responsible for producing ESP [26,54], so it has a high rate of protein production, and consequently needs an active UPP to deal with the mistranslated proteins. The nature of misfolded proteins will be different in hatch fluid compared with the miracidium however: the envelope is much more involved in the production of proteins for secretion, so hatch fluid proteasomal substrates will have originated in the endoplasmic reticulum rather than in the cytosol. In contrast, the miracidium is short-lived and does not secrete proteins whilst it is in the egg. It needs to find and penetrate a snail, and as it does so without feeding it must conserve ATP. It has been calculated that 300-400 ATP molecules are used during the degradation of one substrate protein through the UPP [41], so we hypothesize that operating the UPP would be too expensive in terms of ATP expenditure for the miracidium. Instead, the miracidium could utilize its high levels of the non-ATP-requiring chaperone Sm-p40 [27] to store misfolded proteins rather than degrade them. It is likely that any misfolded proteins associating with Sm-p40 are effectively excluded from the UPP because Sm-p40 does not contain the tetratricopeptide repeat motifs that are found in other common miracidial heat shock proteins such as HSP70 and HSP90 [27,55-57]. The tetratricopeptide repeats are important because they interact with the E3 ubiquitin ligase CHIP (C-terminus of HSP70-interacting protein) and thereby form the bridge linking the chaperones and the UPP [58,59]. Although CHIP has never been localised to the miracidium, it is present in the $S$. mansoni transcriptome (http://www.genedb.org/genedb, accession number Sm03288).

To our knowledge, this is the first study addressing the question of protein turnover in the schistosome egg. We have shown that the undeveloped egg has a more active UPP and a more complex proteasome subunit expression pattern than the developed egg, consistent with the egg adopting the (highly regulated) UPP and not the (uncontrollable and fast) apoptotic pathway to degrade its vitelline cells. We have also established that the sub-shell envelope has a more complex proteasome subunit expression profile than the miracidium, thereby highlighting the crucial importance of the hitherto unstudied envelope in the biology of the egg.

\section{Acknowledgement}

Funding for this research was provided by a Biotechnology and Biological Sciences Research postgraduate studentship to William Mathieson.

\section{Appendix A. Supplementary data}

Supplementary data associated with this article can be found, in the online version, at doi:10.1016/j.molbiopara.2010.10.005.

\section{References}

[1] Clurman BE, Sheaff RJ, Thress K, Groudine M, Roberts JM. Turnover of cyclin E by the ubiquitin-proteasome pathway is regulated by cdk2 binding and cyclin phosphorylation. Genes Dev 1996;10:1979-90.

[2] Friedman J, Xue D. To live or die by the sword: the regulation of apoptosis by the proteasome. Dev Cell 2004;6:460-1

[3] Muratani M, Tansey WP. How the ubiquitin-proteasome system controls transcription. Nat Rev Mol Cell Biol 2003;4:192-201.

[4] Hegerl R, Pfeifer G, Puhler G, Dahlmann B, Baumeister W. The three-dimensional structure of proteasomes from thermoplasma acidophilum as determined by electron microscopy using random conical tilting. FEBS Lett 1991;283:117-21

[5] Kopp F, Dahlmann B, Hendil KB. Evidence indicating that the human proteasome is a complex dimer. J Mol Biol 1993;229:14-9.

[6] Zwickl P, Grziwa A, Puhler G, Dahlmann B, Lottspeich F, Baumeister W. Primary structure of the Thermoplasma proteasome and its implications for the structure, function, and evolution of the multicatalytic proteinase. Biochemistry 1992:31:964-72.

[7] Baumeister W, Walz J, Zuhl F, Seemuller E. The proteasome: paradigm of a self-compartmentalizing protease. Cell 1998;92:367-80.

[8] Orlowski M, Wilk S. Catalytic activities of the $20 \mathrm{~S}$ proteasome, a multicatalytic proteinase complex. Arch Biochem Biophys 2000;383:1-16.

[9] Chandu D, Nandi D. Comparative genomics and functional roles of the ATP-dependent proteases Lon and Clp during cytosolic protein degradation. Res Microbiol 2004;155:710-9.

[10] Mason GG, Murray RZ, Pappin D, Rivett AJ. Phosphorylation of ATPase subunits of the 26S proteasome. FEBS Lett 1998;430:269-74.

[11] Rivett AJ, Bose S, Brooks P, Broadfoot KI. Regulation of proteasome complexes by gamma-interferon and phosphorylation. Biochimie 2001;83:363-6.

[12] Kimura Y, Takaoka M, Tanaka S, Sassa H, Tanaka K, Polevoda B, et al $\mathrm{N}$ (alpha)-acetylation and proteolytic activity of the yeast $20 \mathrm{~S}$ proteasome. J Biol Chem 2000;275:4635-9.

[13] Sumegi M, Hunyadi-Gulyas E, Medzihradszky KF, Udvardy A. 26S proteasome subunits are O-linked $\mathrm{N}$-acetylglucosamine-modified in Drosophila melanogaster. Biochem Biophys Res Commun 2003;312:1284-9.

[14] Zhang F, Su K, Yang X, Bowe DB, Paterson AJ, Kudlow JE. O-GlcNAc modification is an endogenous inhibitor of the proteasome. Cell 2003;115:715-25.

[15] Verma R, Chen S, Feldman R, Schieltz D, Yates J, Dohmen J, et al. Proteasoma proteomics: identification of nucleotide-sensitive proteasome-interacting proteins by mass spectrometric analysis of affinity-purified proteasomes. Mol Biol Cell 2000;11:3425-39.

[16] Thrower JS, Hoffman L, Rechsteiner M, Pickart CM. Recognition of the polyubiquitin proteolytic signal. EMBO J 2000;19:94-102.

[17] Hicke L. Protein regulation by monoubiquitin. Nat Rev Mol Cell Biol 2001;2:195-201.

[18] Nassar N, Horn G, Herrmann C, Scherer A, McCormick F, Wittinghofer A. The 2.2 A crystal structure of the Ras-binding domain of the serine/threonine kinase c-Raf1 in complex with Rap1A and a GTP analogue. Nature 1995;375:554-60.

[19] Cavanaugh JE. Role of extracellular signal regulated kinase 5 in neuronal survival. Eur J Biochem 2004;271:2056-9.

[20] Hirano Y, Yoshinaga S, Ogura K, Yokochi M, Noda Y, Sumimoto H, et al. Solution structure of atypical protein kinase C PB1 domain and its mode of interaction with ZIP/p62 and MEK5. J Biol Chem 2004;279:31883-90.

[21] Hofmann K, Bucher P. The UBA domain: a sequence motif present in multiple enzyme classes of the ubiquitination pathway. Trends Biochem Sci 1996;21:172-3.

[22] Bertolaet BL, Clarke DJ, Wolff M, Watson MH, Henze M, Divita G, et al. UBA domains of DNA damage-inducible proteins interact with ubiquitin. Nat Struct Biol 2001;8:417-22.

[23] Wilkinson CR, Seeger M, Hartmann-Petersen R, Stone M, Wallace M, Semple C, et al. Proteins containing the UBA domain are able to bind to multi-ubiquitin chains. Nat Cell Biol 2001;3:939-43.

[24] Pearce EJ, MacDonald AS. The immunobiology of schistosomiasis. Nat Rev Immunol 2002;2:499-511.

[25] Neill PJ, Smith JH, Doughty BL, Kemp M. The ultrastructure of the Schistosoma mansoni egg. Am J Trop Med Hyg 1988;39:52-65. 
[26] Ashton PD, Harrop R, Shah B, Wilson RA. The schistosome egg: development and secretions. Parasitology 2001;122:329-38.

[27] Mathieson W, Wilson RA. A comparative proteomic study of the undeveloped and developed Schistosoma mansoni egg and its contents: the miracidium, hatch fluid and secretions. Int J Parasitol 2009.

[28] Guerra-Sa R, Castro-Borges W, Evangelista EA, Kettelhut IC, Rodrigues V. Schistosoma mansoni: functional proteasomes are required for development in the vertebrate host. Exp Parasitol 2005;109:228-36.

[29] Nabhan JF, El-Shehabi F, Patocka N, Ribeiro P. The 265 proteasome in Schistosoma mansoni: bioinformatics analysis, developmental expression, and RNA interference (RNAi) studies. Exp Parasitol 2007;117:337-47.

[30] Castro-Borges W, Cartwright J, Ashton PD, Braschi S, Guerra Sa R, Rodrigues $\mathrm{V}$, et al. The $20 \mathrm{~S}$ proteasome of Schistosoma mansoni: a proteomic analysis. Proteomics 2007;7:1065-75.

[31] Smithers SR, Terry RJ. The infection of laboratory hosts with cercariae of Schistosoma mansoni and the recovery of adult worms. Parasitology 1965;55:695-700.

[32] Curwen RS, Ashton PD, Johnston DA, Wilson RA. The Schistosoma mansoni soluble proteome: a comparison across four life-cycle stages. Mol Biochem Parasito 2004; 138:57-66.

[33] Tanaka K, Yoshimura T, Ichihara A. Role of substrate in reversible activation of proteasomes (multi-protease complexes) by sodium dodecyl sulfate. JBiochem (Tokyo) 1989;106:495-500.

[34] Stein RL, Melandri F, Dick L. Kinetic characterization of the chymotryptic activity of the 20S proteasome. Biochemistry 1996;35:3899-908.

[35] Mahajan-Miklos S, Cooley L. Intercellular cytoplasm transport during Drosophila oogenesis. Dev Biol 1994;165:336-51.

[36] Foley K, Cooley L. Apoptosis in late stage Drosophila nurse cells does not require genes within the H99 deficiency. Development 1998;125:1075-82.

[37] Nezis IP, Stravopodis DJ, Papassideri I, Robert-Nicoud M, Margaritis LH. Stage-specific apoptotic patterns during Drosophila oogenesis. Eur J Cell Biol 2000;79:610-20.

[38] Boros DL, Pelley RP, Warren KS. Spontaneous modulation of granulomatous hypersensitivity in schistosomiasis mansoni. J Immunol 1975;114:1437-41.

[39] Smyth JD, Halton DW. The physiology of trematodes. 2nd ed. Cambridge: Cambridge University Press; 1983.

[40] Hanna J, Hathaway NA, Tone Y, Crosas B, Elsasser S, Kirkpatrick DS, et al. Deubiquitinating enzyme Ubp6 functions noncatalytically to delay proteasomal degradation. Cell 2006;127:99-111.

[41] Benaroudj N, Zwickl P, Seemuller E, Baumeister W, Goldberg AL. ATP hydrolysis by the proteasome regulatory complex PAN serves multiple functions in protein degradation. Mol Cell 2003;11:69-78.

[42] Verjovski-Almeida S, DeMarco R, Martins EA, Guimaraes PE, Ojopi EP, Paquola AC, et al. Transcriptome analysis of the acoelomate human parasite Schistosoma mansoni. Nat Genet 2003;35:148-57.

[43] Tyas L, Brophy VA, Pope A, Rivett AJ, Tavare JM. Rapid caspase-3 activation during apoptosis revealed using fluorescence-resonance energy transfer. EMBO Rep 2000;1:266-70.
[44] Al-Adhami BH, Thornhill J, Akhkha A, Doenhoff MJ, Kusel JR. The properties of acidic compartments in developing schistosomula of Schistosoma mansoni. Parasitology 2003;127:253-64.

[45] Bogitsh B]. Cytochemistry of gastrodermal autophagy following starvation in Schistosoma mansoni. J Parasitol 1975;61:237-48.

[46] Levine B, Klionsky DJ. Development by self-digestion: molecular mechanisms and biological functions of autophagy. Dev Cell 2004;6:463-77.

[47] Mpakou VE, Nezis IP, Stravopodis DJ, Margaritis LH, Papassideri IS. Programmed cell death of the ovarian nurse cells during oogenesis of the silkmoth Bombyx mori. Dev Growth Differ 2006;48:419-28.

[48] Velentzas AD, Nezis IP, Stravopodis DJ, Papassideri IS, Margaritis LH. Stage-specific regulation of programmed cell death during oogenesis of the medfly Ceratitis capitata (Diptera, Tephritidae). Int J Dev Biol 2007;51: 57-66.

[49] Erasmus DA. Schistosoma mansoni: development of the vitelline cell, its role in drug sequestration, and changes induced by Astiban. Exp Parasitol 1975;38:240-56.

[50] Cheever AW, Duvall RH. Single and repeated infections of grivet monkeys with Schistosoma mansoni: parasitological and pathological observations over a 31-month period. Am J Trop Med Hyg 1974;23:884-94.

[51] Pellegrino J, Coelho PM. Schistosoma mansoni: wandering capacity of a worm couple. J Parasitol 1978;64:181-2.

[52] Schubert U, Anton LC, Gibbs J, Norbury CC, Yewdell JW, Bennink JR. Rapid degradation of a large fraction of newly synthesized proteins by proteasomes. Nature 2000;404:770-4.

[53] Kostova Z, Wolf DH. For whom the bell tolls: protein quality control of the endoplasmic reticulum and the ubiquitin-proteasome connection. EMBO J 2003;22:2309-17.

[54] Schramm G, Gronow A, Knobloch J, Wippersteg V, Grevelding CG, Galle J, et al. IPSE/alpha-1: a major immunogenic component secreted from Schistosoma mansoni eggs. Mol Biochem Parasitol 2006;147:9-19.

[55] Lee DH, Goldberg AL. Proteasome inhibitors cause induction of heat shock proteins and trehalose, which together confer thermotolerance in Saccharomyces cerevisiae. Mol Cell Biol 1998;18:30-8.

[56] Bercovich B, Stancovski I, Mayer A, Blumenfeld N, Laszlo A, Schwartz AL, et al Ubiquitin-dependent degradation of certain protein substrates in vitro requires the molecular chaperone Hsc70. J Biol Chem 1997;272:9002-10.

[57] Doong H, Rizzo K, Fang S, Kulpa V, Weissman AM, Kohn EC. CAIR-1/BAG-3 abrogates heat shock protein-70 chaperone complex-mediated protein degradation: accumulation of poly-ubiquitinated Hsp90 client proteins. J Biol Chem 2003;278:28490-500.

[58] McClellan AJ, Frydman J. Molecular chaperones and the art of recognizing a lost cause. Nat Cell Biol 2001;3:E51-3.

[59] Cyr DM, Hohfeld J, Patterson C. Protein quality control: U-box-containing E3 ubiquitin ligases join the fold. Trends Biochem Sci 2002;27:368-75. 